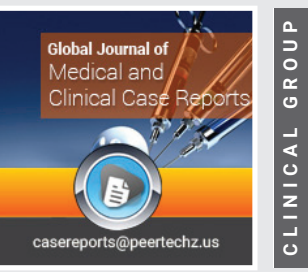

\title{
The case of acute psychotic
}

\section{episode treatment in patient with}

\section{myasthenia gravis}

\author{
Patrycja Pajor*, Maria Jankowska and Marek Jarema \\ Department of Psychiatry, Institute of Psychiatry \& Neurology, Warsaw, Poland
}

Received: 28 May, 2021

Accepted: 08 June, 2021

Published: 09 June, 2021

*Corresponding author: Patrycja Pajor, Department of Psychiatry, Institute of Psychiatry \& Neurology, Warsaw, Poland, Tel: +48 667740999;

E-mail:ppajor@ipin.edu.pl, patrycja.pajor@wp.pl

Keywords: Myasthenia gravis; Uveitis; Antipsychotic treatment

https://www.peertechzpublications.com

\section{Check for updates}

\begin{abstract}
A seventy-one old male patient with no previous $\mathrm{Hx}$ of mental disorders including alcohol use and with no family $\mathrm{Hx}$ of mental disorders was admitted to psychiatric ward due to acute aggression, agitation, excessive irritability and lack olf sleep. He suferred from myasthenia gravis for years and was treated chronically with ambenonium $20 \mathrm{mg}$ daily. Because of comorbidity of uveitis with macular edema he received treatment with prednisolone $70 \mathrm{mg}$ daily. Because of acute psychotic symptoms the treatment with olanzapine up to $20 \mathrm{mg} / \mathrm{d}$ was introduced without effect. The treatment was switched to haloperidol $10 \mathrm{mg} / \mathrm{d}$ with gradual improvement of patient's behaviour. He was discharged from the hospital with indication to continue psychiatric, ohpthalomogic, and neurological outpatient care.
\end{abstract}

\section{Case report}

A 71-year-old patient, with no medical history of psychiatrical treatment, was admitted to the hospital because of psychomotor agitation, irritability, decreased need for sleep and aggression. The onset of the symptoms had been observed approximatelly one month before hospital admission, symptoms gradually worsened with time. Patient was brought to the hospital by the police, immobilized and handcuffted due to destructive, disorganized behaviour. According to his family for years he has been irritable and nervous, periodically abusing alcohol.

This patient has been suffering from myasthenia gravis with a mild clinical course for 6 years and was treated chronically with ambenonium $20 \mathrm{mg}$ per day, currently with no neurological symptoms. Patient also had a history of uveitis with macular edema. For ophthalmic reasons, 6 months ago treatment with oral corticosteroids was initiated, starting with a dose of $70 \mathrm{mg} / \mathrm{d}$ prednisolone, in decreasing weekly doses. The treatment was temporarily discontinued due to SARS-CoV-2 infection. Taking the above-mentioned drugs by the patient resulted in psychomotor agitation, insomnia and irritability. Despite these symptoms, the therapy was recontinued three months ago: corticosteroids at a dose of $50 \mathrm{mg} / \mathrm{d}$ predniosolone were restarted, in a similar scheme; recently with the dose of $17,5 \mathrm{mg}$ per day methotrexate $20 \mathrm{mg}$ once a week was added to the treatment.
During the initial psychiatric consultation in the emergency room patient was uncooperative, actively negativistic, psychomotor agitated, aggressive towards the personel. The patient was admitted mandatory to a psychiatric ward. On admission the patient was comprehensively oriented, in difficult contact, negativistic, did not answer questions, irritable, meticulous in his statements. He showed vivid affect, accelerated thinking, elevated mood, expressed delusions, denied suicidal thoughts. In laboratory tests, slight leukocytosis, neutropenia, increased transaminases were shown. Physical examination did not show any abnormalities.

Patient was diagnosed with acute psychotic disorder due to known physiological condition [ICVD-10: F06.3]. Other possible mental disorders such as Brief Psychotic D/O, Bipolar Mania, Psychosis NOS were excluded in the basis of fact that the symptoms have started after the use of medications for uveitis (corticosteroids). This was the main reason that other psychiatric diagnoses have been excluded. At the beginning sedatives were not given because of the history of myasthenia gravis. Due to the lack of cooperation, considerable agitation, delusional thinking, active aggression towards the staff and the need for repeated use of restraint, olanzapine $10 \mathrm{mg} /$ day i.m. was administered. The treatment was well tolerated so the dose was increased to $20 \mathrm{mg} / \mathrm{d}$ i.m with the addition of hydroxyzine PRN. No adverse effects and no deterioration of the neurological status were observed. After 7 days of treatment, the patient was 
still disorganized, maladjusted, vulgar, he uttered delusional content. Due to the lack of improvement, olanzapine was discontinued and haloperidol at a dose of $10 \mathrm{mg} / \mathrm{d}$ i.m. was started. Tretment was well tolerated. After 7 days of haloperidol treatment patient's condition gradually improved, mood was balanced, the patient became critical of the spoken delusional content, but still remained large, periodically coprolal. When patent's state became more stabile the noncontrast CT scan of the brain was obtained with no abnormalities shown. The form of treatment was changed to oral haloperidol at a dose of $10 \mathrm{mg} /$ day, after 6 days the patient was discharged home in a state of improvement, with reccomentadion of continuing treatment in an outpatient setting.

\section{Discussion}

Myasthenia gravis is an autoimmune neuromuscular disease in which antibodies against the acetylcholine receptor are produced. The severity of symptoms ranges from mild eye symptoms, the weakness and fatigue of various muscle groups to the life-threatening condition of myasthenic crisis. In some patients with myasthenia gravis, muscle weakness is limited to the muscles of the eyeball [1]. Patients with this type of myasthenia gravis are at risk of developing generalized disease especially in the early stages of the disease. Ninety percent of people who have had the ocular form for more than 2 years will remain in this subgroup [2]. Observational studies [3] suggest that prednisolone treatment reduces the risk of developing generalized myasthenia gravis [4]. Patients with myasthenia gravis often respond well to low doses (10-30 mg every other day) of corticosteroids alone [5]. Although the neuropsychiatric symptoms associated with the use of high doses of corticosteroids (defined as greater than $40 \mathrm{mg}$ of prednisone or its equivalent) are often complex and unpredictable, they may be used within the first weeks of steroid treatment [6]. It is estimated that about $20 \%$ of patients receiving treatment may develop a psychiatric disorder such as mania, psychosis or depression [7]. Manic episodes are the most frequent manifestations of a corticosteroid-induced neuropsychiatric disorder. The literature suggests that patients treated for steroid-induced mania are more likely to present severe psychotic symptoms than patients who have mania not induced by substances. Persecutory delusions, auditory hallucinations, and disorganized behavior are the dominant symptoms among this group of patients $[4,8,9]$. It should be underlined that many medications can worsen the symptoms of myasthenia gravis, including antipsychotics, antidepressants, sedatives. Antipsychotic drugs carry a low risk of worsening myasthenia gravissymptoms in comparison with medicines from other groups [10]. Antipsychotics with affinity for muscarinic cholinergic receptors, such as olanzapine, quetiapine, clozapine, should be used with caution. The use of olanzapine for this patient was justified by the known sedative properties of this drug (along with antipsychotic activity) and this drugi is concidered as first-choice medication for aggresive psychotic patients. The classic antipsychotics such as haloperidol, amisulpride or paliperidone were described as safer [11] which is confirmed by our case report.

\section{Conclusion}

Regardless of the fact that sedative medications are contraindicated in patients with myasthenia gravis, in some conditions there is the need to treat patients with antipsychotics. This case indicates that antipsychotic treatment administered due to psychotic episode with severe aggresive behaviour constituting in immediate harm to oneself and others - to a patient suffering from myasthenia gravis, may result in beneficial effect without side effects and without worsening of myasthenia symptoms. We present this report to underline that regard the limitation of antipsychotic use in patients suffering frrom both myasthenia gravis and uveitis, the use of a classic antipsychotic instead of atypical antipsychotic drug which proved to be uneffective was sucessful.

\section{References}

1. Gilhus NE, Verschuuren JJ (2015) Myasthenia gravis: subgroup classification and therapeutic strategies. Lancet Neurol 14: 1023-1036. Link: https://bit.ly/3z3LkFM

2. Kerty E, Elsais A, Argov Z, Evoli A, Gilhus NE (2014) EFNS/ENS Guidelines for the treatment of ocular myasthenia. Eur $\mathrm{J}$ Neurol 21: 687-693. Link: https://bit.ly/3v70J4R

3. Benatar M, Kaminski $H$ (2012) Medical and surgical treatment for ocular myasthenia. Cochrane Database Syst Rev 12: CD005081. Link: https://bit.ly/3v2nlhE

4. Mehyar M, Rodrigue F, Tiffany L, Robert $P$ (2012) Medications and Myasthenia Gravis (A Reference for Health Care Professionals), Link: https://bit.ly/3ggsL8H

5. Dubovsky AN, Arvikar S, Stern TA, Axelrod L (2012) The neuropsychiatric complications of glucocorticoid use: steroid psychosis revisited. Psychosomatics 53: 103-115. Link: https://bit.ly/3wZ9iAa

6. Verma R, Wolfe GI, Kupersmith MJ (2021) Ocular myasthenia gravis - How effective is low dose prednisone long term? J Neurol Sci 420: 117274. Link: https://bit.ly/3w6VMuj

7. Bolanos SH, Khan DA, Hanczyc M, Bauer MS, Dhanani N, et al. (2004) Assessment of mood states in patients receiving long-term corticosteroid therapy and in controls with patient-rated and clinician-rated scales. Ann Allergy Asthma Immunol 92: 500-505. Link: https://bit.ly/3v0NLWr

8. Ciriaco M, Ventrice P, Russo G, Scicchitano M, Mazzitello G, et al. (2013) Corticosteroid-related central nervous system side effects. J Pharmacol Pharmacother 4: S94- S98. Link: https://bit.ly/2T6RDIb

9. Wolkowitz OM, Burke H, Epel ES, Reus VI (2009) Glucocorticoids Mood, memory, and mechanisms. Ann N Y Acad Sci 1179: 19-40. Link: https://bit.ly/3ipWLIb

10. Trillenberg $P$, Katalinic A, Junghanns K, Thern J (2021) Worsening of myasthenia due to antiepileptic, antipsychotic, antidepressant, and sedative medication: An estimation of risk based on reporting frequency. Eur J Neurol. Link: https://bit.ly/3gbRZoQ

11. She S, Yi W, Zhang B, Zheng Y (2017) Worsening of Myasthenia Gravis Afte Administration of Antipsychotics for Treatment of Schizophrenia: A Case Report and Review of Literature. J Clin Psychopharmacol 37: 620-622. Link: https://bit.ly/3gxwyyT 